The ephemeral as a creation of the architectural object. From exaltation to denial of place

PALABRAS CLAVE - ARPUITECTURA EFÍMERA · TIEMPO MEMORIA $\cdot$ SENSIBILIDAD $\cdot$ LUCAR

KEYWORDS - EPHEMERAL ARCHITECTURE · TIME · MEMORY SENSITIVITY PLACE

\title{
Lo efímero como creación del objeto arquitectónico
}

\section{De la exaltación a la negación del lugar}

KATHERINE OREJUELA BRANCH · Cali, Valle del Cauca, Colombia·katherine.orejuela@correounivalle.edu.co

Fecha recepción: 29 de julio 2020 · Fecha aceptación: 24 de noviembre 2020

\section{INTRODUCCION: LO EFIMERO COMO MEDIACIÓN ENTRE SUJETO-MUNDO}

Es a duración, sin embargo, pensar lo efímero como un concepto relacionado con el sujeto supone descifrar su naturaleza en relación a los objetos que denominamos con este adjetivo y cómo estos inciden en el significado del lugar. Por lo tanto, este artículo pretende plantear lo efímero como condición en el sujeto creador a partir de reconocer la ciudad como un lugar de escenarios espacio-temporales de vivencias, lo efímero como característica del objeto creado a partir de la resistencia del monumento a su temporalidad; la exaltación del lugar a través de un símbolo y testigo de lo ya ido y la incidencia de la Revolución Industrial en la sinonimia de lo montable y desmontable como efímero; lugar funcional. Por esto, se propone la sensibilidad como sinonimia de lo efímero para pensar el objeto arquitectónico que niega el lugar en nuestra época.

\section{ABSTRACT}

The ephemeral is associated with the fleeting or with the short term; however, thinking of the ephemeral as a concept related to the subject supposes to

de-incrypt its nature in relation to the objects we call with this adjective and how they affect the meaning of the place. Therefore, this article aims to present the ephemeral as a condition in the creative subject by recognizing the city as a place of space-time scenarios of experiences, the ephemeral as a characteristic of the object created from the resistance of the monument to its temporality; the exaltation of the place through a symbol and witness what has already sone and the incidence of the Industrial Revolution in the synonymy of the mountable and dismountable as ephemeral; functional place. For this reason, sensitivity is proposed as a synonym for the ephemeral to think about the architectural object that denies the place in our time.
Este escrito es resultado de una reflexión filosófica de la investigación "Método y Composición: pensar la arquitectura efímera", seleccionada y financiada por la Universidad del Valle. Cuyo primer resultado se centra en la comprensión del concepto de lo efímero y su importancia en la construcción del monumento o el objeto arquitectónico que se da en el lugar. Para ello se abordará i. la exaltación del lugar desde el sujeto creador (el monumento) y ii. la negación del lugar desde el objeto creado (lo programable), con el fin de dar cuenta del significado de este en nuestra época (siglo XXI).

El interrogante planteado por Lynch (1975) ¿̇De qué tiempo es este lugar? Nos sirve de guía para reflexionar acerca de la incidencia del tiempo sobre el lugar como espacio construido y el objeto arquitectónico como representación de este último. En este sentido el lugar ¿̇Cómo se transforma? ¿̇Para qué resiste? ¿¿ué representa? ¿Cuándo se preserva? ¿̇ué es por hoy por hoy?

Como señala Kant en la Estética Trascendental (2007), del concepto de espacio único e infinito podemos extraer diversos espacios solo con base a la presuposición de un único y mismo espacio, pues cada uno forma parte de dicha totalidad. Sin embargo, en su categoría como concepto es origen y principio del espacio construido.
En el primero está implícita una narración metafísica del cómo queremos habitar ese espacio a través de lo construido y el segundo es la representación material cuyos elementos constitutivos incorporan y hacen conscientes al sujeto de la experiencia de los fenómenos del espacio. Es decir, el espacio como concepto y representación se construyen a razón del habitar Para Masís (2018):

Se podría afirmar que la arquitectura no se crea en un lugar, sino que produce un lugar, pero esa producción no se tiene que confundir con el planteamiento y la resolución físico-técnica del espacio; por el contrario, se debe entender como una producción simbólica que manifiesta nuestra propia existencia. (2018, p. 138)

El espacio construido (lugar) es sinónimo del espacio conceptual respectivamente. La narración que nace del concepto y prevalece en lo representado es recreada por el sujeto, esto hace que la experiencia pueda trascender los límites de lo físico y así construir un significado propio de lo percibido. El lugar como espacio construido se funda en la fugacidad del tiempo, es decir, la arquitectura es muestra fehaciente de la temporalidad y a la vez de la percepción que tiene el sujeto sobre el paso del mismo. Es un intento de atrapar el tiempo a través de los monumentos que materializan y se convierten en lugares de memoria. Estos: 
[No] tienen referentes en la realidad. O más bien, son ellos mismos su propio referente, signos que envían así, signos en estado puro. No es que no tengan contenido, ni presencia física ni historia; todo lo contrario. Sino eso que hace los lugares de memoria y aquello por lo que, precisamente, escapan a la historia. Templum: recorte en lo indeterminado de lo profano -espacio o tiempo, tiempo y espacio- de un círculo al interior del cual todo cuenta, todo simboliza, todo significa, En este sentido, el lugar de memoria en un lugar doble; un lugar de exceso encerrado en sí mismo, cerrado en su identidad y recogido sobre su nombre, pero constantemente abierto en sus significaciones (Nora, 1984, p. XLI).

En el presente, el sujeto se vale del lugar de la memoria-donde se inscribe el monumento-, como conciencia histórica; por la cual, describe la transformación o evolución de las cosas con respecto a otras que van surgiendo (Lynch, 1975). Las huellas del pasado están en la mente del sujeto y este las reconoce en el mundo exterior como un conglomerado de hechos concretos representados a través de objetos arquitectónicos que le producen una sensación de familiaridad y, por ende, los valora como monumentos.

El objeto arquitectónico como obra de arte contiene y revela al mismo tiempo; representa el significado de un mundo vivido, lo percibido, recordado y experimentado. Dicho estado se produce de forma narrativa a través de la dualidad de los elementos inmateriales y materiales. Es una esencia no figurativa que le permite al objeto arquitectónico con su racionalidad, geometría y forma evidenciar dicha retórica existencial, dar un significado inconsciente a su materialidad a través de la metáfora, la analogía y el símbolo. Para Pallasmaa (2014) "Las obras de arte y de arquitectura existen, pues, en los ámbitos de la física y de la metafísica, la realidad y la ficción, la construcción y la imagen, en el uso y el deseo; todo a un mismo tiempo" (p. 118). La tensión entre las dos realidades (subjetiva- objetiva) ha de prevalecer como soporte del carácter existencial que desde siempre le ha correspondido ejercer al objeto arquitectónico como lugar de la memoria: responder a las necesidades tanto funcionales como psíquicas del sujeto. La labor del sujeto creador está, entonces, en hacerlas reconciliables en su propósito de exaltar el lugar.

Ahora, es importante aclarar que "todo lugar es un espacio, pero no todo espacio es un lugar" (Masís, 2018, p. 157). Construir un lugar de memoria implica contribuir a la experiencia existencial a partir del significado (el concepto del espacio), el significante de lo percibido (el monumento) y aquello que simboliza el lugar (la memoria). Sin embargo, a partir de la segunda Revolución Industrial el significado del concepto espacio se concibe en razón de su "optimización" y el objeto arquitectónico (pabellón) como objeto programable con características efímeras a través de lo montabledesmontable. Esto con el propósito de obedecer a las nuevas necesidades de la época: reunir en un mismo espacio un sin número de sujetos entorno al constante cambio espacial que implicaba el comercio y consumo de los avances técnico-científicos de la industrialización.

Este tipo de espacios son de paso o transición, dominados así por el cambio constante al que son sometidos y Auge los reconoce como los nolugares, ya que en la no construcción del lugar niegan al mismo a través de su ausencia. Masís (2018) así lo expone:

En los no-lugares, se tiende a manifestar una programación excesiva, que tergiversa la riqueza de nuestros modos singulares de habitar, de concretar y de convivir, de modo que el sujeto aprende a confortarse en un espacio hiperplanificado, (...). Esta impersonalización del espacio es comercializada con el disfraz de la comodidad, traída a nuestras vidas como un privilegio que, en su paso destruye el concepto de comunidad, la idea de convivencia y el disfrute del recorrido (p. 162).
Finalmente, estos no-lugares como espacios de tránsito o de paso, se han consolidado en nuestra época como producto de los fenómenos del consumo y la obsolescencia, debido al individualismo tanto del sujeto creador como del consumidor. A esto se le suma la aceleración del cambio que es reflejado finalmente en la incapacidad de erigir objetos arquitectónicos que sean memorables y construyan la identidad del lugar donde se implantan. Dicho de otro modo, los no-lugares de nuestra época si bien poseen características físicas como la materialidad para delimitar y "conceptualizar" el espacio, no son definibles como lugares por las relaciones fugaces que ahí se establecen y la asimilación de una identidad cosmopolita o de ninguna dentro del cambio. Sin embargo, Masís (2018) cuando cita a Auge nos hace reflexionar sobre la "polaridad" entre el lugar y el no-lugar, para pensar la tensión entre lo permanente y lo pasajero:

El lugar y el no lugar son más bien polaridades falsas: el primero no queda nunca completamente borrado y el segundo no se cumple nunca totalmente: son palimpsestos donde se reinscribe sin cesar el juego intrincado de la identidad y de la relación. (2018, pp. 164-165)

Llegado a este punto, es pertinente exponer cómo el concepto de lo efímero ha influido en la construcción del objeto arquitectónico que se da en el lugar.

Lo efímero es entendido como un adjetivo que sirve para describir lo pasajero o de corta duración; sin embargo, es una condición creadora en el sujeto. Como concepto es un medio por el cual representa, simboliza y percibe el mundo, mientras que el lugar es el producto en el que se inscriben dichas relaciones. El problema se presenta cuando es interpretado desde lo desechable, es decir, desde la sensibilidad de la moda, ya que esto ha llevado a sesgar la concepción del lugar para satisfacer únicamente aspectos sensitivos, emocionales y sensibles ligados al placer retiniano. De ahí que, cambio, moda, inmaterialidad, flexibilidad 
conceptual, seducción, arquiescultura, reciclaje, programable, y basura, son solo algunos términos encerrados por la interpretación de la sensibilidad a través de conceptos como tendencia, ligereza y obsolescencia por los cuales se concibe el lugar en nuestra época.

Por ello, surge el deseo de exponer la subjetividad que le pertenece al lugar como principio de su creación. Esto en razón de recordar, tanto al lector en general como a los dedicados a hacer arquitectura, que el objeto arquitectónico como representación del lugar es sólo el resultado final de una concepción interna que lo puede negar o no según la percepción que tiene el sujeto creador sobre el mundo exterior, reflejándose, finalmente, en el valor estético.

Para desentrañar el concepto de lo efímero fue menester tomar de referencia la Historia de la idea del tiempo de Bergson (2018), esto permitió indagar sobre la percepción que tiene el sujeto del tiempo frente a la transformación del lugar. En principio, desarrollar esta premisa implicó incorporar la obra Arte efímero y espacio estético de Torrijos (1988), con el propósito de exponer lo efímero como proceso subjetivo desde el cual se conciben los objetos del mundo exterior. En segundo lugar, la obra La imagen corpórea: imaginación e imaginario en la arquitectura de Pallasmaa (2014), resultó útil al evidenciar cómo el objeto arquitectónico puede atrapar - liberar el tiempo según el propósito por el cual ha sido creado. En tercer lugar, Rovelli a través de El orden del tiempo (2018) nos acerca al cambio como precedente en la producción de este objeto en cada época. Finalmente, la obra ¿̇De qué tiempo es este lugar? de Lynch (1975), revela al objeto arquitectónico en su papel orientador del sujeto como un intento de conectarse desde el presente con los diferentes tiempos.

Lo efímero al ser sinónimo del transcurrir del tiempo adquiere una doble condición, dado que las anteriores relaciones se establecen tanto en el sujeto como en el objeto. En el sujeto como creador se indagó sobre su resistencia a la temporalidad, esto a través de la producción de una arquitectura espacio-temporal determinada por el gusto de una época y categorizada por su belleza como una obra universal. Los monumentos evidencian la participación de la subjetividad en la creación del mundo. Se reconoció en la obra Historia de la arquitectura moderna de Benevolo (1979) la evolución del objeto arquitectónico a partir de la segunda mitad del siglo XIX hasta el primer tercio del siglo XX, hechos o acontecimientos históricos que han marcado su significado efímero en cada época, por los cuales se identificó cómo el surgimiento de nuevos materiales, técnicas y representaciones impulsadas en paralelo a un fin capitalista de las nuevas producciones de la época, lo categorizaron como un objeto montable-desmontable y posteriormente, en el siglo XXI se identificó a través de la obra La estetización del mundo de Lipovetsky (2015) un capitalismo artístico que ha prevalecido hasta nuestros días donde la sensibilidad resulta ser un mercado que produce objetos arquitectónicos estético-emocionales como lugares espectaculares de turismo cultural.

Como resultado se verá por qué es tan importante reconocer lo efímero en la creación del lugar y de qué manera se manifiesta en la ciudad a través de actividades generadas por el sujeto, en los objetos monumentos como representaciones de los hechos históricos contundentes y en las características materiales y estructurales del objeto, así como las interpretaciones dadas en nuestros días sobre lo efímero para inmaterializar el objeto arquitectónico.

Se concluirá señalando porque es pertinente el uso del concepto de lo efímero como principio generador de hechos, acontecimientos, actividades y objetos arquitectónicos a partir de los cuales se interpreta qué es y para qué sirve el lugar. Cuáles son los limitantes cuando se trata de conservar este tipo de lugares y cómo lo primero puede abrir paso a una mediación entre lo permanente y lo pasajero para que estos lugares puedan resurgir y ser conservados. Finalmente, más que responder un interrogante, se trata de cuestionar desde el oficio del arquitecto de qué manera el objeto arquitectónico puede enriquecer el espíritu del lugar y, a la vez, se puede conservar en el tiempo aún con los cambios del contexto.

\section{METODOLOGÍA: LOS CONCEPTOS DE LO EFÍMERO COMO METODOLOGÍA DE SU COMPRENSIÓN}

Revelar el sentido de lo efímero como concepto creador implicó un primer acercamiento desde dos significados: el primero dado por la Real Academia Española con adjetivos como "pasajero, de corta duración" (RAE, 2014), y el segundo a su etimología proveniente del griego bizantino $\varepsilon ф \eta \mu \varepsilon \rho о \varsigma$ (ephëmeros) que significa "de un día". Sin embargo, para hacer extensivo su significado, fue necesario cuestionarlo en relación al tiempo y definirlo paralelamente desde su actuar en la arquitectura como representación del lugar. Esto se logró teniendo en cuenta las siguientes definiciones:

CAMBIO. Un conjunto de brevedades que constituyen la permanencia. Para Bergson (2018) el tiempo no está constituido por lo continuo o permanente, sino, por una multiplicidad de cambios donde lo efímero está implícito. Por ende, la permanencia estaría constituida por un conjunto de cambios y el cambio es la cualidad de la realidad del hombre que este intenta atrapar a través de la materialización del objeto, de un signo, que se convertirá en algo efímero dependiendo de la intención del artista y de los materiales que utilice en la construcción del mismo. Experiencia: Una realidad subjetiva que se vivencia. Para Torrijos (1988), lo efímero es inherente a toda creación artística y se vivencia en la experiencia sujeto-mundo. Es un medio por el cual el sujeto le otorga significados o símbolos a los objetos que él crea y es por esta naturaleza de inmaterialidad que ha sido limitado en su comprensión como el origen de estos; sin embargo, se debe reconocer en lo efímero el principio que constituye el imaginario del sujeto para construir una representación del mundo. Unidad: abarca las categorías del 
tiempo. Para Pallasmaa (2014) la arquitectura como representación de lo efímero logra manipular el tiempo en razón de afectar desde diferentes grados de intensidad la experiencia del sujeto. Estas variables dependen si el objeto arquitectónico ha sido concebido para contener el tiempo a través de la conservación de una memoria o la explotación del mismo por medio de un objeto programable. Repetible: permite emerger nuevos objetos en cada época. Para Rovelli (2018) el cambio que se constata en lo efímero, posibilita en el sujeto la comprensión del mundo exterior, es decir, al captar la repetición de las eventualidades, el sujeto entra en correlación con el lugar de las representaciones y la transformación de las mismas, como un acto auto reconocimiento. Material: es la representación del mundo exterior. Para Lynch (1975) lo efímero como condición interior del sujeto se manifiesta en la creación de objetos en el mundo exterior por los cuales se logra conectar desde el presente con el pasado y el futuro.

Debido a la interacción entre los diferentes conceptos emergentes del tiempo en relación con la arquitectura, se logró corroborar que lo efímero abarca tanto al sujeto como al objeto, por ello lo efímero es ontológico y funcional respectivamente, siendo posible pensarlo como acto de creación y para comprobar dicha conclusión se categorizó lo efímero desde dos perspectivas:

i. Lo efímero como condición en el sujeto creador: la ciudad como escenario contenedor de lugares en donde el sujeto interactúa con el mundo exterior (Torrijos, 1988), y cuyas partes emergen como testigos de hechos contundentes que abren paso a la creación de los monumentos (Rossi, 1999).

ii. Lo efímero como característica en el objeto creado: reconocer la revolución industrial (1850-1914) como hecho que divide en dos la concepción de la arquitectura; de una lenta a una rápida forma de transformar el lugar, por ello y debido a los nuevos avances técnico- científicos de la época se integró el concepto de lo efímero en la producción del objeto arquitectónico: montable y desmontable (Benevolo, 1979).

Sin embargo, para cuestionar la forma de producir el objeto arquitectónico desde la tercera parte del siglo XX a nuestros días, bastó con fijarse en la "evolución" del capitalismo ya no desde lo montable y desmontable como sinonimia de lo efímero, sino como lo artístico ligado a una sensibilidad para crear objetos generadores de emociones, es decir, arquitecturas atractivas y espectaculares cuyo valor reside en satisfacer el placer sensitivo (Lipovetsky, 2015). A partir de esto fueron surgiendo interpretaciones de dicha sensibilidad como: la tendencia, para referirse al cambio constante (Lipovetsky, 2015); lo ligero, como representación de la inmaterialidad (Lipovetsky, 2016) y la obsolescencia; desde donde se programa la duración en función de materializar un objeto arquitectónico en cada una de estas sensibilidades (Pardo, 2010).

\section{RESULTADOS: LO QUE NOS DICE LO EFÍMERO}

Confrontar lo efímero con conceptos relacionados con el tiempo en el transcurso de la historia, reveló lo siguiente:

Lo efímero abarca la fugacidad de cada una de las unidades del tiempo: minutos, horas, días, años, lustros, décadas, entre otros. Al hacer referencia a estos con términos como acontecimiento, momentáneo, instantáneo o infinito, dicho concepto impulsa al sujeto a la acción para que éste represente el lugar a través del objeto arquitectónico, erigiéndolo con una perdurabilidad obediente al propósito por el cual fue creado. De ahí que el tiempo transforme el lugar "Su solidez es infinitamente superior a la de una fijeza que no es más que un arreglo efímero entre movilidades" (Bergson, 2018) y sea manipulable en la obra. Pallasmaa se refiere a la experiencia de manipular el tiempo "Ciertamente, todas las artes tienen que ver con el tiempo y su manipulación. El tiempo de la experiencia del arte puede compactarse, acelerarse, ralentizarse, invertirse y detenerse" (2014, p. 96). Por ello, el objeto arquitectónico existe en cada uno de estos términos debido a su permanencia en el tiempo, el sujeto puede conocer y reconocerse en los hechos contundentes o acontecimientos que son representados por dicho objeto.

Por consiguiente, en cada época de manera repetitiva surgen nuevos objetos que le permiten al sujeto captar, comprender, y describir la historia de un lugar. La experiencia del mundo resulta estar en el interior del sujeto y es representada desde el exterior en función de relaciones temporales, a partir de esta estructura se organizaron los hechos, los objetos, los ritmos y ciclos sobre una idea de tiempo exterior. Tanto sujeto como el objeto comparten una red de conceptos efímeros como acontecimientos, eventos, sucesos y temporalidades que permiten al sujeto percibir el mundo desde el cambio y no desde la permanencia, así como lo expone Rovelli: "(...) el mundo como un conjunto de eventos, de procesos, es el modo que mejor nos permite captarlo, comprenderlo, describirlo. Es el único modo compatible con la relatividad. El mundo no es un conjunto de cosas, es un conjunto de eventos" (2018, pp. 76-77).

Desde dicho orden establecido en el espaciotiempo exterior, el presente hace una conexión directa con el pasado a través del monumento y con el futuro a través de su planificación; el sujeto se vale de la materialización de lo efímero para crear el mundo exterior, un mundo sólo perceptible desde el presente. Esta lucidez que el sujeto tiene sobre el paso del tiempo en su presente es un estado interno del pasado y el futuro. Lynch expresa al respecto: "En realidad, el pasado y el futuro, aunque se refiere a sucesos más distantes, solamente existen en este mismo tiempo inmediato y gracias a los procesos presentes del recuerdo y de la anticipación" (1975, p. 144)

Lo anterior retornó al diálogo en común entre tiempo-objeto para replantear lo efímero 
como origen de la arquitectura de un lugar, pero también de su alcance en relación sujeto-objeto, es decir, de su presencia como manifestación interna y de su representación exterior por medio del objeto arquitectónico. La materialización de lo efímero en el espaciotiempo es la representación de la expresión estética del sujeto a través de la producción de símbolos por los cuales crea el mundo exterior. Por eso, lo efímero es ontológico y funcional respectivamente, siendo posible pensar lo efímero como una condición en el sujeto y como característica en el objeto.

En el sujeto lo efímero resulta ser una condición, es decir, el carácter de lo efímero le permite configurar su imaginario y contribuir a que éste pueda construir una representación del mundo, el objeto arquitectónico existe en el lugar gracias a que el sujeto participa de él, lo crea desde su tiempo interior y lo consume desde el tiempo exterior. Torrijos se refiere a lo inherente del concepto como: "(...) independientemente de su perdurabilidad, no existe un espacio transformado separado de una vivencia del tiempo ni ninguna creación que no participe, aunque sea de forma fugaz, en una representación de la cultura con un principio y un fin" (1988, p. 18).

En el objeto, lo efímero da cuenta de su concepción para responder a los cambios externos, es decir, se presenta como una característica del objeto mismo. Esto incluye sus elementos constitutivos como son los materiales y la estructura, convirtiéndolo en un objeto capaz de ser transformado en el contexto donde se implante. La temporalidad de los elementos permite representar a través del objeto una multiplicidad de estilos y suplir diversas necesidades del sujeto. Al fin de comprender cómo se interpreta lo efímero en el objeto según la época, para Torrijos la duración del objeto depende en sí del propósito a cumplir: "Algunas de estas transformaciones, cuando pretenden transmitir un mensaje de perdurabilidad y proyectarse hacia el futuro, se realizan con materiales como piedra; otras, cuya única finalidad es su manifestación temporal, utilizan materiales perecederos" (1988, p. 18).

\section{DISCUSIÓN: LO EFÍMERO COMO CONDICIÓN EN EL SUJETO CREADOR}

Lo efímero es un concepto mediador entre el sujeto-mundo por el cual interactúa, crea y consume la obra. Es decir, es una cualidad inherente a la creación artística al ser una condición en las relaciones del sujeto con el mundo exterior. Esto le permite crear símbolos, otorgar significados y relacionarse con objetos que contribuyen a construir una representación y el espíritu del lugar. Por lo tanto, se puede reconocer en este concepto una cualidad de la cual surge el principio de toda creación artística.

La ciudad emerge como un espacio contenedor de lugares donde el sujeto además de materializar y expresarse desde lo efímero, logra comprender e identificar las representaciones efímeras de los acontecimientos y hechos históricos y, por lo cual, a través de su percepción las consume y altera la imagen del lugar. Para Torrijos (1988) ante la constante alteración de sus elementos

La obra urbana va más allá de la suma de los edificios que la componen y puede convertirse en una obra de arte de relación (...) donde todo producto, sea o no arquitectónico, es modificado por aquello que existe alrededor. (p. 30)

La ciudad además de permitir al sujeto interactuar con el mundo exterior desde lo efímero, también se reconoce como un espacio dinámico y vivo donde se producen, transforman y conservan ciertos objetos arquitectónicos. Una interpretación del pensamiento de Torrijos es manifestada por Mehrotra y Vera (2015) cuando reflexionan sobre la ciudad de Kumbh Mela:

(...) el futuro de las ciudades depende menos de la reorganización de los edificios e infraestructura, y más de nuestra habilidad de imaginar el paisaje tecnológico, material, social, y económico de forma más abierta y versátil. Esto quiere decir que debemos diseñar ciudades (o al menos parte de ellas) como estrategias provisorias, que crecen alineando su escala temporal y las soluciones que conceptualizamos en nuestro imaginario urbano (pp. 23-24)

Rossi (1999) evidencia las categorías de cada una de las partes de la ciudad y describe el valor del espacio público por la colectividad de su uso en el que el habitante y la comunidad pueden existir para el consumo estético del lugar a través de distintas formas de expresión: "Lo que hay en común se refiere al carácter público, colectivo de estos elementos; esta característica de cosa pública, hecha por la colectividad, es de naturaleza esencialmente urbana" (pp. 155157).

Se identifica en el uso público del espacio un conjunto de escenarios donde los sujetos interactúan, cuya especialidad es inclusiva y las vivencias son colectivas: ideologías, creencias, fiestas, rituales o memorias sobre un mismo escenario en común. Para hacer extensiva la cualidad efímera de este lugar se abordó desde Lynch (2008) una descripción previa a las subcategorías correspondientes: "Un escenario físico vívido e integrado, capaz de generar una imagen nítida, desempeña así mismo una función social. Puede proporcionar la materia prima para los símbolos y recuerdos colectivos de comunicación del grupo" (p. 13). Este impacto a la experiencia según Lopera (2013), es lo significativo del lugar:

Esto es importante en el planteamiento de la relación entre imagen, espacio y memoria, pues el espacio, más allá de su condición física, se configura como un escenario de experiencias, en donde de acuerdo con la profundidad del fenómeno vivenciado por el sujeto se determina el recuerdo de la experiencia, que tal y como se mencionó anteriormente se construye en términos imaginativos (p. 104) 
1. Plaza de San Pedro. Fuente: Opus Dei Communications Office on Foter.com / CC BY-NC-SA, 2014.

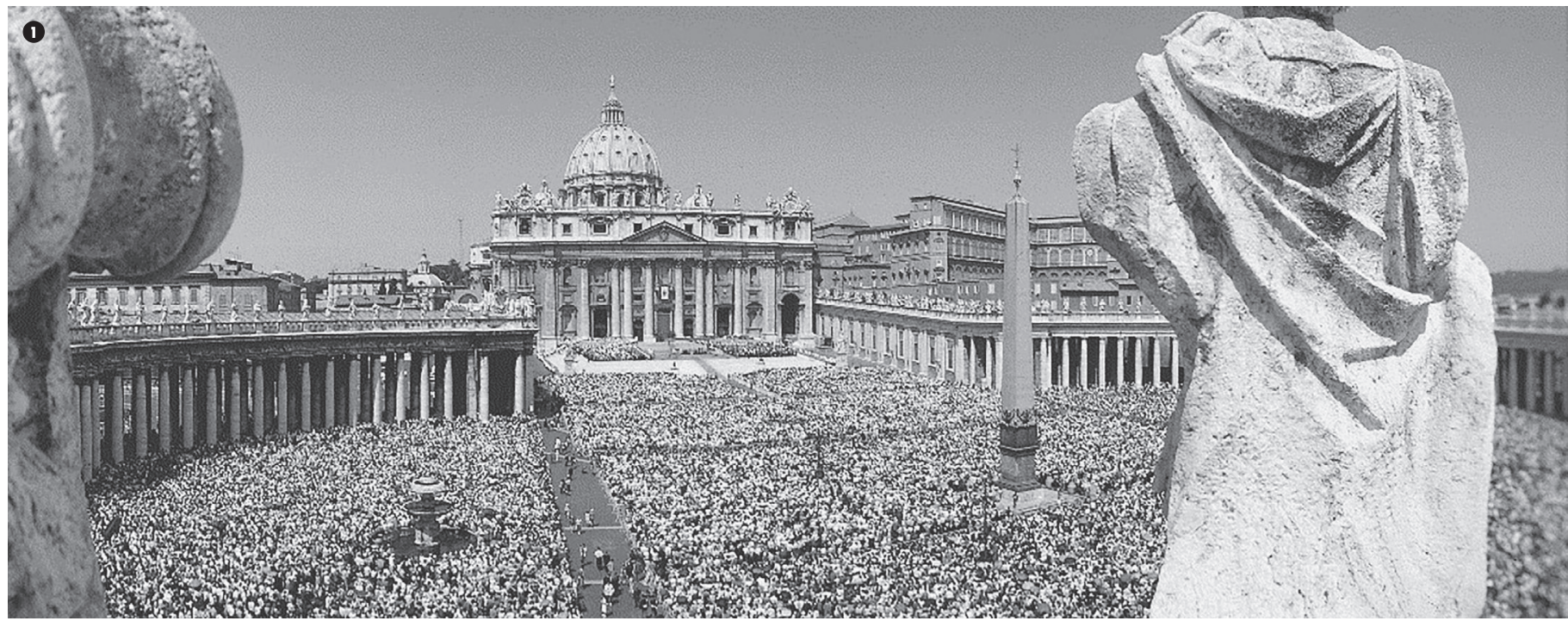

El sujeto atrapa los hechos a través de los monumentos con la consideración de representar aquello que debe permanecer, recrearse, perdurar, y reconocerse -por ello son considerados efímeros-. Sin embargo, desde el presente puede conservarlos, restaurarlos, rehabilitarlos y reutilizarlos con el fin de proporcionarle longevidad a lo representado en el lugar y según Rossi (1999) una continua experimentación del pasado: "(...) el pasado es en parte experimentado ahora y que, desde el punto de vista de la ciencia urbana, puede ser éste el significado que hay que dar a las permanencias; éstas son un pasado que aún experimentamos" (p. 99). Esto para Vecco(2020) sería lo material (tangible) e inmaterial (intangible) del "genius loci", como parte inherente y enriquecedora que le da sentido a un lugar:

Preserving the genius loci as the cultural and architectural identity of a place, ensuring its permanence in the collective memory and transmissibility over time, means fully understanding the functional, typological, stylistic and constructive reasons from which a place originates (p. 230) ${ }^{[1]}$.

Lo efímero como condición en el sujeto le otorga un significado existencial (intangible) al objeto arquitectónico (tangible). La afectación de la percepción frente a la vivencia de lo construido genera un cúmulo de experiencias que le van otorgando identidad y cualidades diferenciadoras a cada lugar, aquello nombrado por Vecco (2020) como "El espíritu del lugar". Si bien, la subjetividad (inmaterial) produce una representación (material), esta última cierra el ciclo: sujeto-objeto-sujeto unificando la experiencia a partir de dicha reciprocidad. Este diálogo se instaura en la memoria colectiva y le permite al lugar resistir al paso del tiempo. Entender el lugar como una relación entre las partes, es decir, una tensión entre objeto-

[1] Preservar el genio loci como identidad cultural y arquitectónica de un lugar, asegurando su permanencia en la memoria colectiva y transmisibilidad a lo largo del tiempo, significa comprender plenamente las razones funcionales, tipológicas, estilísticas y constructivas de las que procede un lugar.

implantación, facilita su lectura en un todo relacionado donde la intervención del primero afecta la estructura del segundo y viceversa. Lo efímero entendido aquí como la manifestación del sujeto, es aquello que permite configurar lo subjetivo que le pertenece por naturaleza a un lugar con espíritu.

\section{LO EFÍMERO COMO CARACTERÍSTICA DEL OBJETO ARQUITECTÓNICO CREADO}

La arquitectura de la revolución industrial: lo montable y desmontable como sinonimia de lo efímero.

Indagar sobre lo efímero como característica del objeto arquitectónico implicó fijar la mirada sobre la necesidad del sujeto a lo largo de su existencia por transformar el espacio en relación al espíritu de cada época (crear un lugar). Por ello se remitió sobre algunos puntos determinantes de la obra de Benevolo, aquellos cercanos a la influencia del segundo periodo de la Revolución Industrial (1850-1914) en la producción del objeto arquitectónico. El autor, identifica en dicha época un cambio categorial 
2. Capilla Notre Dame Du Haut. Fuente: frans 16611 on Foter.com / CC BY, 2013.

3. Crystal Palace. Fuente: Special Collections at Johns Hopkins University on Foter.com / CC BY, 2011.

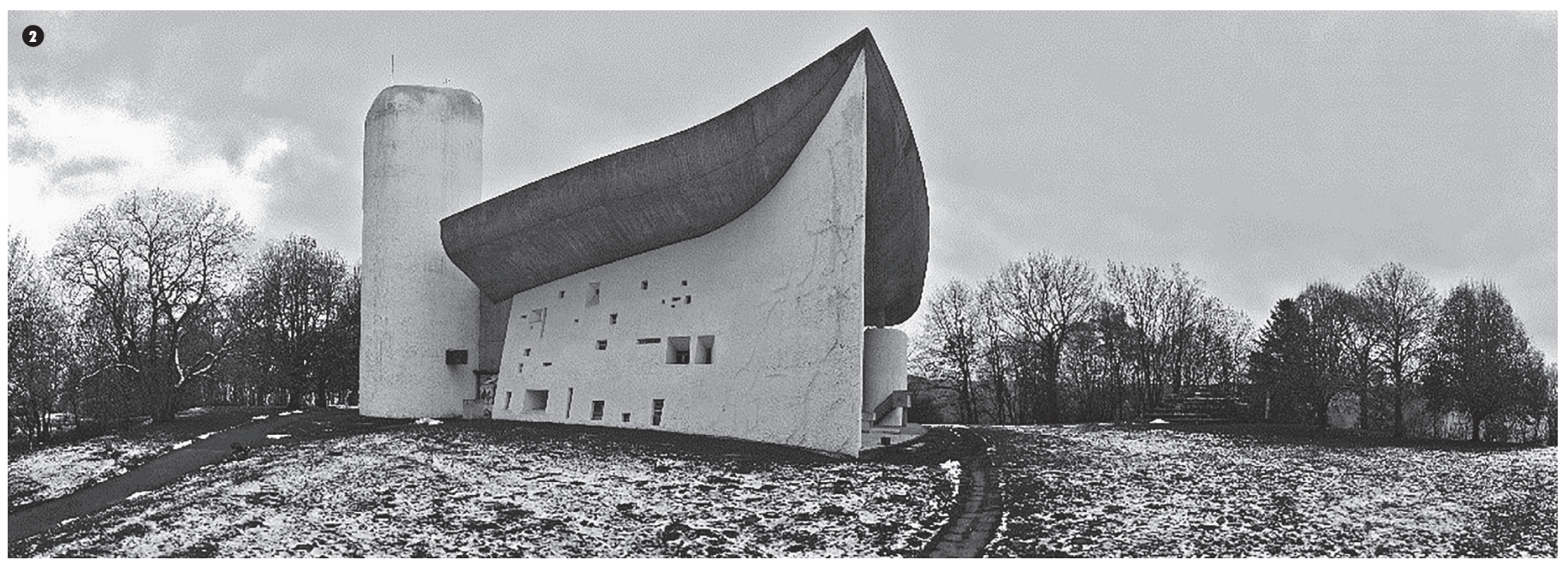

"La relativa continuidad de los sistemas tradicionales no impide, claro está, que el arte de construir sufra transformaciones durante este periodo, ni tampoco la aparición de nuevos problemas" (1979, p. 35).

Este periodo es un hecho histórico contundente que divide la historia de la arquitectura en cuanto a su concepción y construcción, debido a los avances técnico-científicos del último tercio del siglo XIX (la geometría, el sistema métrico decimal y la evolución de materiales como el hierro y vidrio). Benevolo nos contextualiza de este cambio cuando expone: "antes, los objetos, modificados muy lentamente, podían considerarse, de hecho, inmóviles, pero hoy las exigencias funcionales más concretas (...) no permiten que se mantenga tal aproximación" (1979, p. 36). En la época se erigieron otro tipo de objetos arquitectónicos destinados para tener una vida limitada (efímera) cuyas características materiales y estructurales le permitían ser construidos con menos tiempo, materialidad y mano de obra, como es el caso del Crystal Palace (1851).

En el siglo XIX la concepción de los objetos arquitectónicos de características efímeras (Pabellones) se erigían con el propósito de albergar y comercializar lo producido por la

3

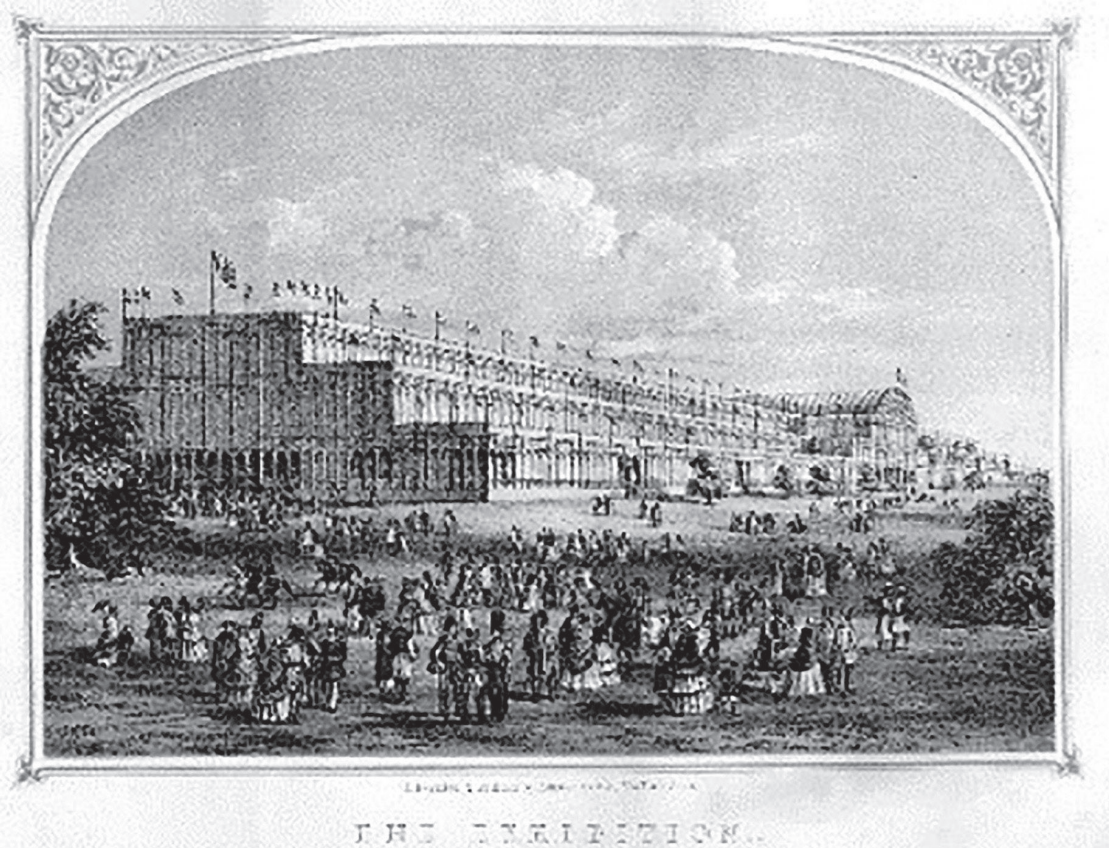

industrialización. Además, proclamaban el espacio construido bajo límites imperceptibles del lugar de implantación como estrategia para optimizar el uso del suelo. Sin embargo, Cimadomo y Lecardane nos introduce un nuevo significado de cambio de siglo: 


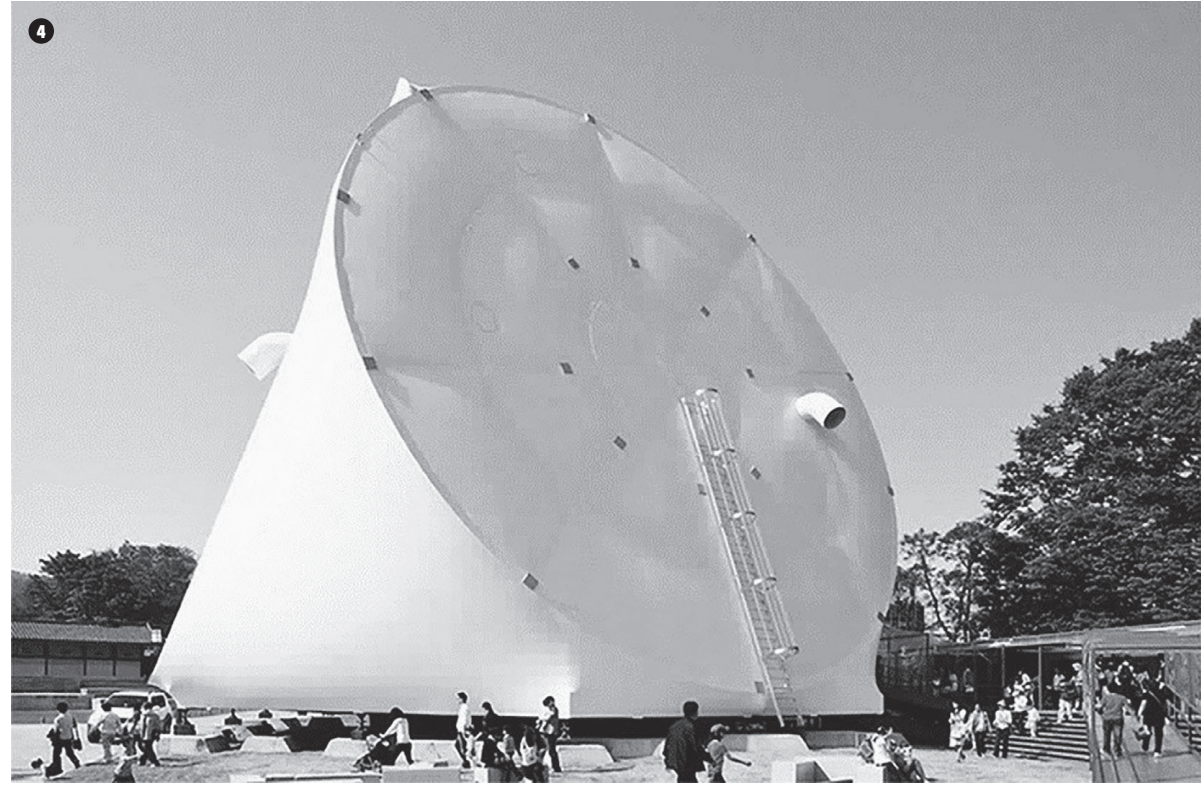

El espacio de exhibición, originalmente concebido para mostrar el progreso de la humanidad y comparar el desarrollo de las naciones, ya no es simplemente el lugar de entretenimiento, información y ficción, sino cada vez más el de la construcción del imaginario urbano de la sociedad de consumo. (2019, p. 145)

En el siglo XXI la mayoría de estos objetos no escatiman uso, debido a que lo efímero ya no es interpretado desde lo montable-desmontable, sino, desde lo liviano y desechable, donde el objeto se consume a través de las emociones producidas por las formas llamativas o apariencias fácilmente modificables. Si bien estos objetos no alteran formalmente el lugar, tampoco hay una apropiación o exaltación del mismo. Así, el lugar público sobre el cual reposa estos objetos arquitectónicos se mimetiza, según lo señala Sansão y Espósito citando a Sennett:

O autor parte de reflexões sobre as relações sociais no espaço público pós-moderno, caracterizado pela proliferação de "corpos passivos" insensíveis ao mundo real, condição em grande parte causada pela experiência da velocidade. Nesse contexto de individualismo, o espaço público se converte em um lugar mais para se passar a vista do que destinado a conversações $\left(2020\right.$, p. 23) ${ }^{[2]}$.

A continuación se apreciará cómo lo montabledesmontable en función de lo desechable ha contribuido en la imagen arquitectónica y el lugar antropológico de consumo turístico, afectando a grandes rasgos la historia: el

[2] El autor comienza con reflexiones sobre las relaciones sociales en el espacio público posmoderno, caracterizadas por la proliferación de "cuerpos pasivos" insensibles al mundo real, condición causada en gran medida por la experiencia de la velocidad. En este contexto de individualismo, el espacio público se convierte en un lugar para ser visto en lugar de estar destinado a las conversaciones.

patrimonio material como objeto de marketing las relaciones sujeto-objeto: búsqueda de experiencias retinianas y; la identidad: adaptabilidad a una nueva imagen cosmopolita. Lo anterior se resume en una construcción visual de impresiones atractivas que son dirigidas a las masas, Pérez (2004) así lo describe:

La imagen de los destinos se asocia a este tipo de acontecimientos, y las motivaciones que atraen a los turistas hacia ellos son las mismas que en cualquier otro tipo de turismo, pero acompañadas de un matiz particular, el disfrutar de algo único y teóricamente irrepetible, combinando entretenimiento, estimulación sensorial, producto e imagen. Son hechos que conjugan autenticidad y comercialización, diversificando su oferta en un intento de atraer al gran público. (p. 317)

\section{LA ARQUITECTURA DE LA TERCERA PARTE DEL SIGLO XX A NUESTROS DÍAS: LA SENSIBILIDAD COMO SINONIMIA DE LO EFÍMERO}

El vínculo entre sensibilidad-época ha permanecido vigente, es por lo cual se garantiza la subjetividad en el objeto arquitectónico evidenciando el papel del sujeto como creador de lugar. Al respecto Lipovetsky (2015) señala: "No hay ninguna sociedad que no se dedique de un modo u otro a un trabajo de estetización o de «artistización» del mundo, (...) al llevar a cabo la humanización y la socialización de los sentidos y los gustos" (p. 11). Según el autor la sensibilidad del siglo XXI que comunica y produce objetos arquitectónicos ha sido guiada por el capitalismo artístico, que es la conquista de lo estético-emocional, es decir, la proliferación de la moda al diseño. Un fenómeno resaltado por Klotz (2006) para referirse a los lugares hostiles donde emergen estas arquitecturas:

(...) la arquitectura para el consumo se realiza en un escenario hostil, donde todo cambia y donde lógicamente el consumidor 
es y debe ser considerado como el centro de atención; donde las modas y las tendencias definen los criterios, donde todo es efímero, pero debe dar -al menos- la apariencia de permanente y donde muchas veces el contexto es una especie de frente de batalla donde luchan distintos creativos, compitiendo por gritar más fuerte que el vecino. (p. 55)

La tendencia de la moda acelera la transformación estética del lugar y por ende la del objeto. Ya no es el objeto arquitectónico efímero en relación de lo montabledesmontable, la planta libre, o el monumento, sino, una relación con lo desechable y lo aparente con el propósito de emocionar al consumidor a través de formas atractivas. Esta nueva estética resulta ser una imagen monótona e internacional y tiene como consecuencia aquello en lo que Enia (2018) hace hincapié: "Este objetivo no puede conseguirse sino imponiendo a la fuerza su figura, agrediendo el contexto y tratándolo con la mayor descortesía: a la exaltación del objeto se acompaña, en este enfoque, una patente negación del lugar". (p. 64)

La sensibilidad gira en torno a una idealización estética que busca satisfacer las emociones y placeres tanto del creador como del consumidor de la obra arquitectónica. Al primero lo incita a imaginar una multiplicidad de estéticas para satisfacer el placer sensitivo del segundo. Este placer obedece en suplir solamente el sentido de la vista. En palabras de Ferreras y Rosero "El predominio de lo visual propiciado por el contexto sociocultural ha influido en las últimas décadas significativamente, reduciendo la riqueza del espacio arquitectónico a un objeto de consumo visual" (2019, p. 22), con el propósito de despertar experiencias sensoriales en el consumidor a través de un diseño emocional y sensitivo. Lipovetsky (2015) cita a Hartmut Esslinger para referirse a ello como un cambio de ideal de siglo: "el principio «la forma obedece a la función» ha sido reemplazado por la «forma obedece a la emoción»" (pp. 209-210), fenómeno que ha ido homogeneizando los lugares alrededor del mundo, dando la sensación de estar aquí como en cualquier otro lugar. Ferretti, Navarrete y Álvarez (2018) exponen lo implícito en este sentido del lugar a partir de un intento por la diferenciación del mismo: "Esta forma de igualación que implica lo global ha llevado a alcanzar la homogeneización de lo urbano en todas nuestras ciudades que, mientras invierten en diferenciarse socioespacialmente, puertas adentro se han igualado a casi todas internacionalmente. (p. 23).

A continuación, cada una las categorías inmersas en la interpretación de lo efímero para la concepción del objeto arquitectónico y la representación del lugar en nuestra época, para Schwarz (2004) "las categorías de lo nuevo, lo innovador, lo visionario o incluso lo utópico se están devaluando sensiblemente" (p. 79). Es decir, lo diferente como propuesta en nuestra época está permeado por la sensibilidad de la moda, lo ligero y lo obsolescente, éstas como parte del modus operandi del sujeto para intervenir, según lo expuesto por Arnau y Gutiérrez (2017) en la deconstrucción del lugar:

El fenómeno de la deconstrucción en arquitectura es tan antiguo, a nuestro parecer, como la arquitectura misma que, desde su prehistoria, no ha dejado de deconstruir su entorno rural o urbano, para ser a su vez deconstruida por sus habitantes para bien o para mal, pero inevitablemente en ambos casos. (p. 123)

Las categorías de lo efímero interpretado como sinonimia de la sensibilidad son:

- Lo efímero interpretado en la sensibilidad de la moda: El capitalismo artístico ha sido el encargado de configurar el objeto arquitectónico en función de las emociones producidas por el cambio constante de la tendencia, esto se evidencia en los centros y locales comerciales, al igual que en el patrimonio cuando se maquilla con nuevas materialidades y estructuras contemporáneas fácilmente reemplazables. Lipovetsky (2015) señala que "lo que vemos exaltado no es otra cosa que el orden mismo de la subjetividad -la del diseñador y la del consumidor- con sus sueños, su afectividad, sus placeres, en otras palabras (...) es la rehabilitación del homo sentiens". (pp. 208-209).

- Lo efímero interpretado en la sensibilidad de lo ligero: En razón de construirse un objeto arquitectónico ligero, surge una arquitectura inmaterial y conceptualmente experimental con formas cargadas de seducción, efectos y sensibilidades como resultado de un híbrido artístico-digital. Lipovetsky (2016) reconoce la herramienta digital como medio de la nueva seducción del objeto arquitectónico: "apoyándose en las herramientas informáticas y materiales de alta tecnología, una de las tendencias de la arquitectura actual se presenta como arquitectura de seducción sobreestetizada, una "arquiescultura» en la que la estructura está al servicio de lo hiperespectacular" (p. 243).

- Lo efímero interpretado en la sensibilidad de lo obsolescente: Frente a los estragos del aumento en la producción de basura emerge una nueva sensibilidad por concebir una arquitectura ligera que actúe en beneficio del cuidado del planeta, empleándose materiales reciclables, transformables y programables. Sobre la reinterpretación del concepto, el uso, la percepción y la forma de la basura es aquello reafirmado por Pardo (2018) cuando expone: "«Basura» es lo que no tiene lugar, lo que no está en su sitio y, por tanto, lo que hay que trasladar a otros sitios con la esperanza de que allí pueda desaparecer como basura, reactivarse, extinguirse: lo que busca otro lugar para poder progresar". (p. 165). 
5. Oficinas Portuarias de Amberes. Fuente: davidpc_on Foter.com / CC BY-NC-SA, 2016.

6. Domo de Papel. Fuente: JAQ'S PhotoStorage on Foter.com / CC BY-NC-ND, 2010.

7. Museo Guggenheim de Bilbao. Fuente: Javier Díaz Barrera (javierdiazbarrera.es) on Foter.com / CC BY-NC-ND, 2017.
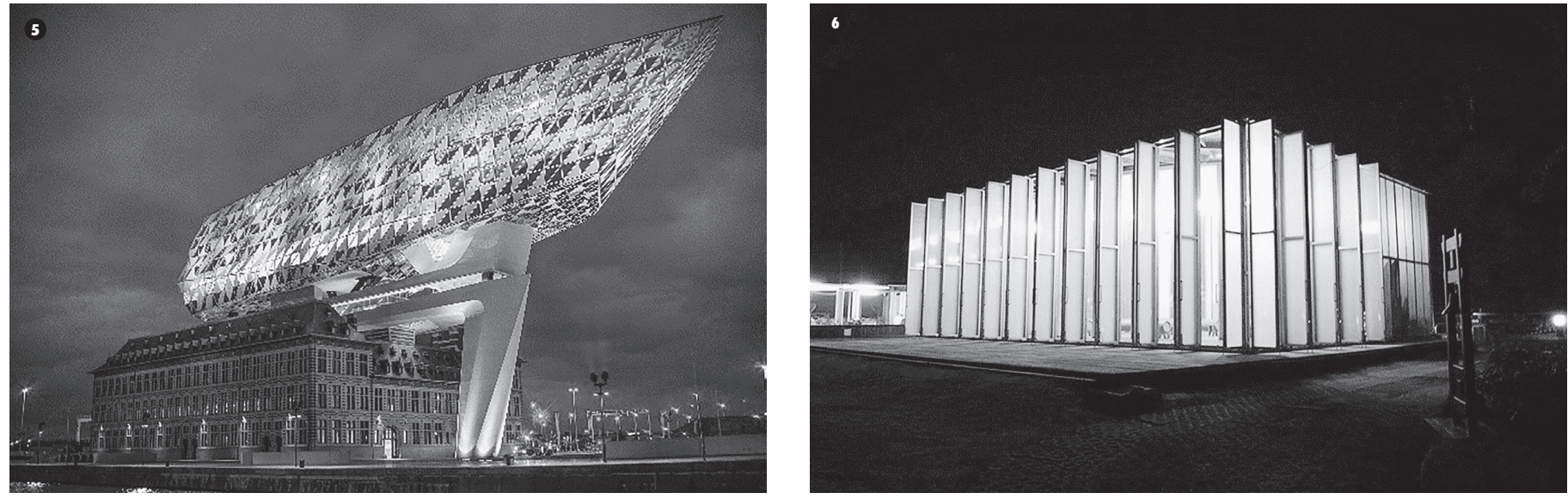

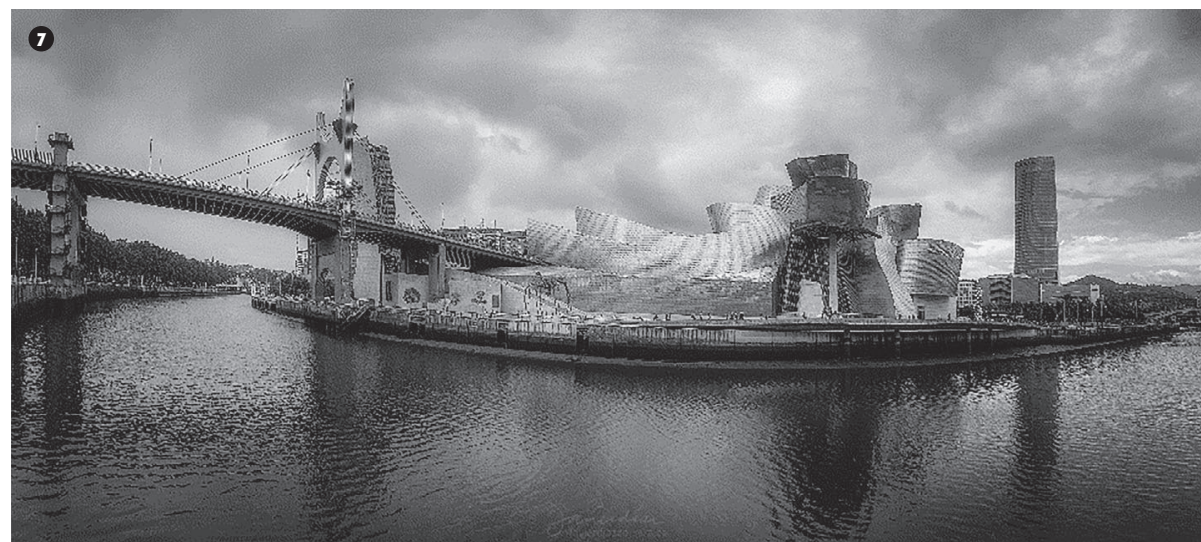

\section{CONCLUSIONES}

1. El principal propósito del escrito es planear qué es y cómo se interpreta el lugar a partir de: i. lo efímero como condición en el sujeto creador: lugar de memoria donde se inscribe la experiencia existencial del sujeto; ii. Lo efímero como característica del objeto creado: un no-lugar como espacio sin identidad producto de los avances técnico-científicos de la época; principio y consolidación del significado del espacio como producto de consumo y obsolescencia en nuestra época. Por un lado, esto implica reflexionar sobre el hacer arquitectura en una época donde el ritmo del cambio es cada vez más acelerado y, por otro lado, confrontar siempre la idea del proyecto ante un ejercicio de introspección: Żqué es hacer una arquitectura del lugar?; ¿̇cuál es el espíritu del lugar que se me es dado para intervenir?, cuando se supone que el objeto arquitectónico es producto de los avances técnicos, científicos o tecnológicos de una época, resultado que ha sido bastante cuestionado desde la Revolución Industrial hasta nuestra época y nos hace topar con la misma pregunta una y otra vez en el surgimiento de cada siglo: ¿̇Qué es la arquitectura?, como si se tratara de una pregunta que cambia de significado en cada época y de ser así por qué no responderla con otra pregunta: ¿̇de las categorías de la arquitectura cuál pertenece a qué lugar?, cuestión que siempre va estar ligada a la intencionalidad del sujeto creador para orientar el sentido y el uso del mismo.

2. Respecto a la intención de mostrar el carácter diferenciador entre una arquitectura que exalta el lugar de una que lo niega, es exponer las limitantes implícitas de cuando a resistir al cambio se trata, y detenerse en cómo las mismas abren un camino entorno a una tensión entre lo permanente y lo pasajero. El mayor problema de conservar el espíritu del lugar sobre todo en el contexto de la ciudad como escenario, vivo y de continua transformación, es que los lugares contenedores de memoria por ser inalterables por su valor simbólico y significativo, tienden a impedir la transformación del contexto convirtiéndole en lugares estáticos, y es en este punto donde entra en juego la resiliencia de los lugares exaltados para mantener su identidad en medio del cambio constante de la sociedad a través de reconstrucción de una correlación entre sujeto-objeto, diferente a la de un capitalismo artístico. 
K. Orejuela • Lo efímero como creación del objeto... • Revista de Arquitectura Vol. 25 - № 39 · Diciembre 2020 • Inconmensurabilidad: La negación del lugar • ISSN 0716-8772 • ISSNe 0719-5427 • pp. 58-68

3. Finalmente, por parte de los dedicados en hacer arquitectura queda en seguir indagando acerca de una categoría de objeto arquitectónico que exalte el lugar donde se implanta y establezca a la vez una correlación con el contexto en cada época. Esto depende de reconocer e interpretar las nuevas necesidades del sujeto y el lugar, pensar de otra manera el papel orientador de este último, así como otro tipo de relación con la ciudad, una más dinámica, adaptable, íntegra e interactiva con su contexto, de ahí que se pueda transformar en consonancia con el continuo cambio y finalmente el espíritu del lugar pueda conservado.

\section{REFERENCIAS BIBLIOGRÁFICAS}

Arnau Amo, Joaquín, \& Gutiérrez Mozo, María Elia. (2017). Semiótica y deconstrucción en Arquitectura: un apunte sobre lenguaje y habitación. Estoa. Revista de la Facultad de Arquitectura y Urbanismo de la Universidad de Cuenca, 6(10), 155-167. https://dx.doi. org/10.18537/est.v006.n010.10

Benevolo, Leonardo. (1979). Historia de la arquitectura moderna. Editorial Gustavo Gilli.

Bergson, Henri. (2018). Historia de la idea del tiempo. Editorial Planeta.

Cimadomo, Guido, \& Renzo, Lecardane. (2019). Las grandes exposiciones del siglo XXI frente a la fragilidad del territorio. Revista del Departamento de Arquitectura de la Universidad de Zaragoza, (13), 136-147.https://doi.org/10.26754/ojs zarch/zarch.2019133909

Enia, Marco. (2018). Borrar la arquitectura: la neutralización del objeto arquitectónico en el siglo XXI. Estoa. Revista de la Facultad de Arquitectura y Urbanismo de la Universidad de Cuenca, 7(13), 97-115. https://dx.doi. org/10.18537/est.v007.n013.a05
Ferreras Cid, Enrique, \& Rosero Añazco, Verónica. (2019). Ciudad compacta, ciudad dispersa. Lenguaje y manipulación en la comunicación gráfica arquitectónica comercial. Estoa. Revista de la Facultad de Arquitectura y Urbanismo de la Universidad de Cuenca, 8(16), 31-53. https:// dx.doi.org/10.18537/est.v008.n016.a02

Ferretti, Mariano Adrián, Navarrete-Escobedo, David, \& Álvarez-Pedrosian, Eduardo. (2018). Las disputas por el sentido y sus lógicas de emplazamiento en la escena urbana neoliberal. Revista de Arquitectura, 20(1), 14-23. https:// dx.doi.org/10.14718/revarq.2018.20.1.1535

Klotz, Mathias. (2006). Arquitectura para el consumo. $A R Q$ (Santiago), (62), 54-56. https://dx.doi. org/10.4067/S0717-69962006000100010

Kant, Immanuel. (2007). Crítica de la razón pura. Ediciones Cohhue

Lynch, Kevin. (2008). La imagen de la ciudad. Editorial Gustavo Gilli.

Lynch, Kevin. (1975). De qué tiempo es este lugar. Editorial Gustavo Gilli.

Lipovetsky, Gilles. (2016). De la Ligereza. Editorial Anagrama.

Lipovetsky, Gilles. (2015). La estetización del mundo. Editorial Anagrama.

Lopera, Jorge. (2013). Reflexiones hermenéuticas sobre el concepto efímero en la fenomenología del espacio de Gaston Bachelard. Iconofacto. (9), 97-105. https://dialnet.unirioja.es/ ejemplar/406037

Mehrotra, Rahul, \& Vera, Felipe. (2015). Reversibility: Desmontando la mega-ciudad efímera más grande del mundo. ARQ (Santiago), (90), 14-25. https://dx.doi.org/10.4067/S0717. 69962015000200003

Masís Morales, Adriana. (2018). Concepción ideográfica del espacio: La singularidad y su valor en la construcción de un mundo habitable. Revista Rupturas, 8(2), 137-168. https://dx.doi. org/10.22458/rr.v8i2.2117
Nora, Pierre. (1984). "Entre memoria e historia: la problemática de los lugares", Lex Lieux de Mémoire, traducción para uso exclusivo de la cátedra Seminario de la historia Argentina. Galimard.

Pallasmaa, Juhani. (2014). La imagen corpórea: imaginación e imaginario en la arquitectura. Editorial Gustavo Gilli.

Pardo, Jose Luis. (2010). Nunca fue tan hermosa la basura. Editorial Círculo de Lectores.

Pérez Barrera, S. (2004). Los "no lugares" espacios del anonimato. Una antropología de la sobremodernidad. Marc Augé. Barcelona: Gedisa, ISBN: 84-7432-459-9; año 1993 (primera edición en español). PASOS Revista De Turismo Y Patrimonio Cultural, 2(1), 149-153. https://doi.org/10.25145/i.pasos.2004.02.026

Rossi, Aldo. (1999). La arquitectura de la ciudad. Editorial Gustavo Gilli.

Rovelli, Carlo. (2018). El orden del tiempo. Editorial Anagrama

Sansão Fontes, Adriana, \& Espósito Galarce, Fernando. (2020). A CONDIÇÃO EFÊMERA NA CIDADE CONTEMPORÂNEA: TRÊS PAVILHÕES TEMPORÁRIOS NO RIO DE JANEIRO (20122018). Arquitecturas del sur, 38(57), 20-37. https://dx.doi.org/10.22320/07196466.2020.3 8.057 .01

Schwarz, Ullrich. (2004). ¿¿Qué es hoy "moderno"? La arquitectura en una sociedad radicalmente modernizada. Anales del Instituto de Investigaciones Estéticas, 26(85). http:// www.scielo.org.mx/scielo.php? script $=$ sci arttext\&pid = S0 1 85-12762004000200006 \&lng $=$ es\&tlng $=$ es.

Torrijos, Fernando. (1988). Arte efímero y espacio estético. Editorial Anthropos Ltda.

Vecco, Marilena. (2020). Genius loci as a metaconcept. Journal of Cultural Heritage., 41 (2020), 225-231. https://doi.org/10.1016/i. culher.2019.07.001 